\title{
Endoscopic Papillary Large Balloon Dilation Reduces the Need for Mechanical Lithotripsy in Patients with Large Bile Duct Stones: A Systematic Review and Meta-Analysis
}

\author{
Mohammad F. Madhoun, ${ }^{1}$ Sachin Wani, ${ }^{2}$ Sam Hong, \\ William M. Tierney, ${ }^{1}$ and John T. Maple ${ }^{1}$ \\ ${ }^{1}$ Division of Digestive Diseases and Nutrition, University of Oklahoma Health Sciences Center, 920 Stanton L. Young Boulevard, \\ WP1345, Oklahoma City, OK 73104, USA \\ ${ }^{2}$ Division of Gastroenterology and Hepatology, University of Colorado, Anschutz Medical Campus, \\ and Veterans Affairs Medical Center, Aurora, Denver, CO, USA
}

Correspondence should be addressed to John T. Maple; john-maple@ouhsc.edu

Received 19 November 2013; Accepted 27 January 2014; Published 6 March 2014

Academic Editor: Tony C.K. Tham

Copyright (C) 2014 Mohammad F. Madhoun et al. This is an open access article distributed under the Creative Commons Attribution License, which permits unrestricted use, distribution, and reproduction in any medium, provided the original work is properly cited.

Background. Removal of large stones can be challenging and frequently requires the use of mechanical lithotripsy (ML). Endoscopic papillary large balloon dilation (EPLBD) following endoscopic sphincterotomy (ES) is a technique that appears to be safe and effective. However, data comparing ES + EPLBD with ES alone have not conclusively shown superiority of either technique. Objective. To assess comparative efficacies and rate of adverse events of these methods. Method. Studies were identified by searching nine medical databases for reports published between 1994 and 2013, using a reproducible search strategy. Only studies comparing ES and ES + EPLBD with regard to large bile duct stone extraction were included. Pooling was conducted by both fixed-effects and random-effects models. Risk ratio (RR) estimates with 95\% confidence interval (CI) were calculated. Results. Seven studies (involving 902 patients) met the inclusion criteria; 3 of 7 studies were prospective trials. Of the 902 patients, 463 were in the ES + EPLBD group, whereas 439 underwent ES alone. There were no differences noted between the groups with regard to overall stone clearance (98\% versus 95\%, RR $=1.01[0.97,1.05] ; P=0.60)$ and stone clearance at the 1 st session $(87 \%$ versus $79 \%, \mathrm{RR}=1.11[0.98$, 1.25]; $P=0.11$ ). ES + EPLBD was associated with a reduced need for ML compared to ES alone (15\% versus $32 \% ; \mathrm{RR}=0.49$ [0.32, 0.74]; $P=0.0008)$ and was also associated with a reduction in the overall rate of adverse events (11\% versus $18 \% ; \mathrm{RR}=0.58$ [0.41, 0.81]; $P=0.001)$. Conclusions. ES + EPLBD has similar efficacy to ES alone while significantly reducing the need for ML. Further, ES + EPLBD appears to be safe, with a lower rate of adverse events than traditional ES. ES + EPLBD should be considered as a first-line technique in the management of large bile duct stones.

\section{Introduction}

Endoscopic retrograde cholangiopancreatography (ERCP) with endoscopic sphincterotomy (ES) represents the standard of care for management of bile duct stones [1]. However, removal of stones $>10 \mathrm{~mm}$ in diameter can be challenging and often requires the use of mechanical lithotripsy (ML) [2, 3]. Dilation of the biliary orifice and distal common bile duct (CBD) after ES using 12- to $20 \mathrm{~mm}$ esophageal or pylorictype balloons was first described in 2003 as an alternative technique to manage large bile duct stones [4]. The safety and efficacy of this technique, termed endoscopic papillary large balloon dilation (EPLBD), have been confirmed in a number of subsequent reports [5-7]. However, studies comparing ES + EPLBD versus ES alone have not conclusively shown the superiority of either technique.

The aims of this systematic review and meta-analysis were to compare ES + EPLBD with ES alone for (i) overall clearance of stone, (ii) clearance of stones at first session, (iii) need for ML, and (iv) rate of adverse events. 


\section{Methods}

2.1. Study Identification. All published studies that compared ES alone versus ES + EPLBD in the management of large bile duct stones were reviewed. Studies were identified by searching nine medical databases including PubMed and Ovid MEDLINE for reports published between 1994 and August of 2013. A reproducible search strategy was employed which combined the terms: "sphincterotomy" OR "ES" and "balloon dilation" and "bile duct stone" OR "choledocholithiasis." References from retrieved articles and abstracts presented at Digestive Diseases Week between 2003 and 2013 were also manually reviewed.

2.2. Study Eligibility. Two investigators (SW, $\mathrm{SH}$ ) independently evaluated studies for inclusion in the systematic review, and any disagreements were adjudicated by the senior investigator (JM). Investigators were not blinded to journal titles, author names, or institutional affiliations. The studies (1) prospectively or retrospectively included comparative analyses between ES and ES + EPLBD, (2) reported (or provided data allowing calculation of) the overall clearance of bile duct stones, and (3) used a balloon diameter $\geq 12 \mathrm{~mm}$ for the ES + EPLBD arm.

2.3. Data Extraction. Two study investigators extracted these data independently for each study: (1) publication year, (2) country of origin, (3) study design, (4) patient demographics, (5) mean CBD diameter, (6) mean diameter of bile duct stone, (7) mean number of stones, (8) presence of periampullary diverticulum, (8) size of endoscopic sphincterotomy, (9) presence of distal common bile duct stricture, (10) use of precut sphincterotomy, (11) stone clearance at first session, (12) overall stone clearance, (13) need for mechanical lithotripsy, (14) need for extracorporeal shock wave lithotripsy, (15) mean number of sessions to achieve complete stone clearance, (16) total procedure time, (17) fluoroscopy time, and (18) rate of adverse events.

2.4. Outcomes for Analysis. The primary outcome of this systematic review and meta-analysis was to compare ES + EPLBD with ES alone for overall clearance of bile duct stones. Secondary outcomes included clearance of the stones at the first session, need for ML, and rate of adverse events.

2.5. Assessment of Study Quality. The Newcastle-Ottawa quality assessment scale was used to assess bias in studies included in this review [8]. This scale rates studies on three sources of bias based on eight criteria: (1) is the case definition adequate?; (2) representativeness of the cases; (3) selection of controls; (4) definition of controls; (5) comparability of cases and controls on the basis of the design or analysis (confounding); (6) ascertainment of exposure; (7) same method of ascertainment for cases and controls; (8) nonresponse rate. Each criterion is worth one star except confounding, which is worth two stars. The Cochrane Collaboration's Risk of Bias (a tool available in Review Manager 5) was used to assess bias in randomized trials meeting eligibility criteria [9]. This tool rates studies on four sources of bias based on six criteria: (1) adequate sequence generation to gauge selection bias; (2) allocation concealment to gauge selection bias; (3) blinding of participants, personnel, and outcome assessors to gauge performance and detection bias; (4) incomplete outcome data to gauge attrition bias; (5) selective reporting to gauge reporting bias; (6) a criterion for other forms of bias. Disagreement between the two extracting authors was resolved by consensus.

2.6. Data Synthesis and Statistical Analysis. The metaanalysis was performed using the Review Manager (RevMan) software, version 4.2.8 (The Nordic Cochrane Centre, Copenhagen, The Cochrane Collaboration) as a summary risk ratio (RR) with 95 percent confidence interval by using the Mantel-Haenszel fixed-effects method [10]. Estimates were also combined using the random-effects model by DerSimonian and Laird [11]. In the absence of significant heterogeneity $(P>0.1)$, the fixed-effects model results were presented. All pooled data were reported with the associated 95\% confidence intervals. All statistical tests were 2 sided, and the significance level was set at $5 \%$. Heterogeneity was assessed by both $\chi^{2}$ and $I^{2}$ statistics $[12,13]$. A $P$ value $<0.10$ (or a large $\chi^{2}$ statistic relative to degrees of freedom) was considered evidence of heterogeneity beyond chance. An $I^{2}$ value greater than $40 \%$ was considered substantial heterogeneity.

\section{Results}

3.1. Study Identifications and Selection. The literature search yielded 39 potentially pertinent studies for inclusion. Thirtyone of these studies were immediately excluded after initial review, most commonly because they presented a case series describing one technique or were review articles. One study met the inclusion criteria but was subsequently excluded as it described the overall rate of clearance among the ES + EPLBD group but not among the ES group [14]. Thus seven studies were included in the final analysis (Figure 1) [15-21]. Manual review of the references of retrieved manuscripts concerning $\mathrm{ES}+\mathrm{EPLBD}$ versus ES alone did not yield any additional studies meeting inclusion criteria for this analysis.

3.2. Description of Variation in Study Methods. Of the seven studies meeting inclusion criteria for the metaanalysis (Table 1), three were prospective randomized studies $[15,17,20]$ and four were retrospective studies $[16,18,19,21]$. One study was published as an abstract [18] and the rest were complete papers [15-17, 19-21]. Four studies were conducted in Korea [15, 17-19], one in Japan [16], one in China [20], and one in Portugal [21]. All studies except one [18] provided detailed patient demographic information. The number of patients included in these studies ranged from 27 to 100 . The range of balloon diameter used in the ES + EPLBD group was between 12 and $20 \mathrm{~mm}$ in the six studies that reported this variable. Four of these studies used balloons with a minimum diameter of $15 \mathrm{~mm}$ [16-18, 20], while two studies used balloons $\geq 12 \mathrm{~mm}[15,21]$. No study specified the exact distribution of balloon diameters used within the range 
TABLE 1: Characteristics of included studies.

\begin{tabular}{|c|c|c|c|c|c|c|c|c|c|c|}
\hline $\begin{array}{l}\text { Study } \\
\text { (year) }\end{array}$ & Country & Type of study & $\begin{array}{l}\text { Number } \\
\text { of } \\
\text { patients } \\
\text { ES/ES + } \\
\text { EPLBD }\end{array}$ & $\begin{array}{c}\text { Age } \\
(\text { mean }) \\
\text { ES/ES + } \\
\text { EPLBD }\end{array}$ & $\begin{array}{l}\text { Gender, } \\
\text { M (\%) } \\
\text { ES/ES + } \\
\text { EPLBD }\end{array}$ & $\begin{array}{c}\text { Mean CBD } \\
\text { diameter } \\
(\mathrm{mm} \pm \mathrm{SD}) \\
\mathrm{ES} / \mathrm{ES}+ \\
\text { EPLBD }\end{array}$ & $\begin{array}{l}\text { Large } \\
\text { balloon } \\
\text { dilation } \\
\text { size } \\
(\mathrm{mm})\end{array}$ & $\begin{array}{l}\text { Mean size of } \\
\text { the stone } \\
(\mathrm{mm} \pm \mathrm{SD}) \\
\mathrm{ES} / \mathrm{ES}+ \\
\text { EPLBD }\end{array}$ & $\begin{array}{c}\text { Size of ES } \\
\text { ES/ES + } \\
\text { EPLBD }\end{array}$ & $\begin{array}{c}\text { Periampullary } \\
\text { diverticulum } \\
(\%) \\
\text { ES/ES + EPLBD }\end{array}$ \\
\hline $\begin{array}{l}\text { Heo } \\
(2007)\end{array}$ & Korea & RCT & $100 / 100$ & $63 / 64$ & $50 / 48$ & N/A & $12-20$ & $\begin{array}{c}15 \pm 0.7 / 16 \pm \\
0.7\end{array}$ & Full/Limited & $45 / 49$ \\
\hline $\begin{array}{l}\text { Itoi } \\
(2009)\end{array}$ & Japan & Retrospective & $48 / 53$ & $73 / 75$ & $58 / 38$ & $\begin{array}{c}18 \pm 4.3 / 17 \pm \\
3.7\end{array}$ & $15-20$ & $\begin{array}{c}15 \pm 3.2 / 15 \pm \\
3.5\end{array}$ & Full/Full & $58 / 47$ \\
\hline $\begin{array}{l}\text { Kim HG } \\
(2009)\end{array}$ & Korea & RCT & $28 / 27$ & $70 / 70$ & $39 / 37$ & $\begin{array}{c}21 \pm 5.7 / 21 \pm \\
6.3\end{array}$ & $15-18$ & $\begin{array}{c}21 \pm 5.2 / 21 \pm \\
4.1\end{array}$ & Full/Limited & $36 / 33$ \\
\hline $\begin{array}{l}\text { Hong GY } \\
(2009)\end{array}$ & Korea & Retrospective & $65 / 70$ & N/A & N/A & N/A & 15 or 20 & N/A & N/A & $49 / 57$ \\
\hline $\begin{array}{l}\text { Kim TH } \\
(2011)\end{array}$ & Korea & Retrospective & $77 / 72$ & $69 / 69$ & $49 / 54$ & $\begin{array}{c}19 \pm 4.4 / 18 \pm \\
3.3\end{array}$ & N/A & N/A & Full/Limited & N/A \\
\hline $\begin{array}{l}\text { Teoh } \\
(2013)\end{array}$ & China & RCT & $78 / 73$ & $73 / 72$ & $51 / 44$ & N/A & 15 & N/A & Full/Limited & NA \\
\hline $\begin{array}{l}\text { Rosa } \\
\text { (2013) }\end{array}$ & Portugal & Retrospective & $43 / 68$ & $73 / 71$ & $35 / 34$ & $\begin{array}{c}16.4 \pm 7.2 / 17.1 \\
\quad \pm 3.4\end{array}$ & $12-18$ & $\begin{array}{c}16.0 \pm \\
6.7 / 16.8 \pm \\
4.4\end{array}$ & N/A & N/A \\
\hline
\end{tabular}

RCT: randomized controlled trial; ES: endoscopic sphincterotomy; EPLBD: endoscopic papillary large balloon dilation; N/A: not available; CBD: common bile duct; SD: standard deviation.

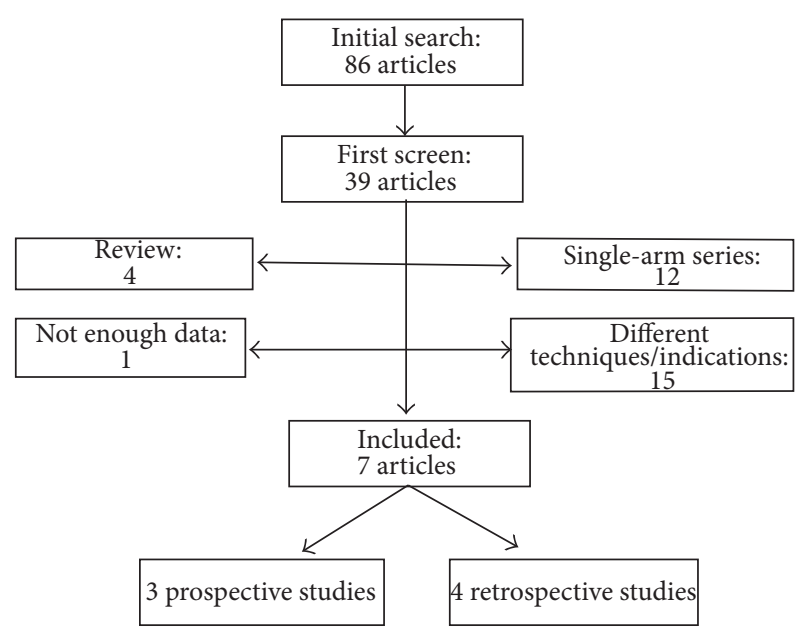

FIGURE 1: Flowchart of the studies included in the meta-analysis.

of permissible balloon sizes. A limited (submaximal) ES was implemented in conjunction with EPLBD in four studies [15, $17,19,20]$, full/maximal ES in one study [16], and two studies did not mention the extent of ES $[18,21]$. All studies reported rates for overall stone clearance and the use of mechanical lithotripsy, and all except one [18] reported rates of clearance at the first session. Three studies reported total procedure time $[16,19,20]$, and one study reported fluoroscopy time [16]. Five studies reported data regarding the size and/or number of biliary stones $[15-17,20,21]$. Among the three prospective randomized trials, randomization was conducted intraprocedurally after obtaining biliary access in two studies $[15,20]$ and prior to ERCP in one study [17].

3.3. Assessment of Study Quality. The assessment of bias in the retrospective studies indicated that three studies were of

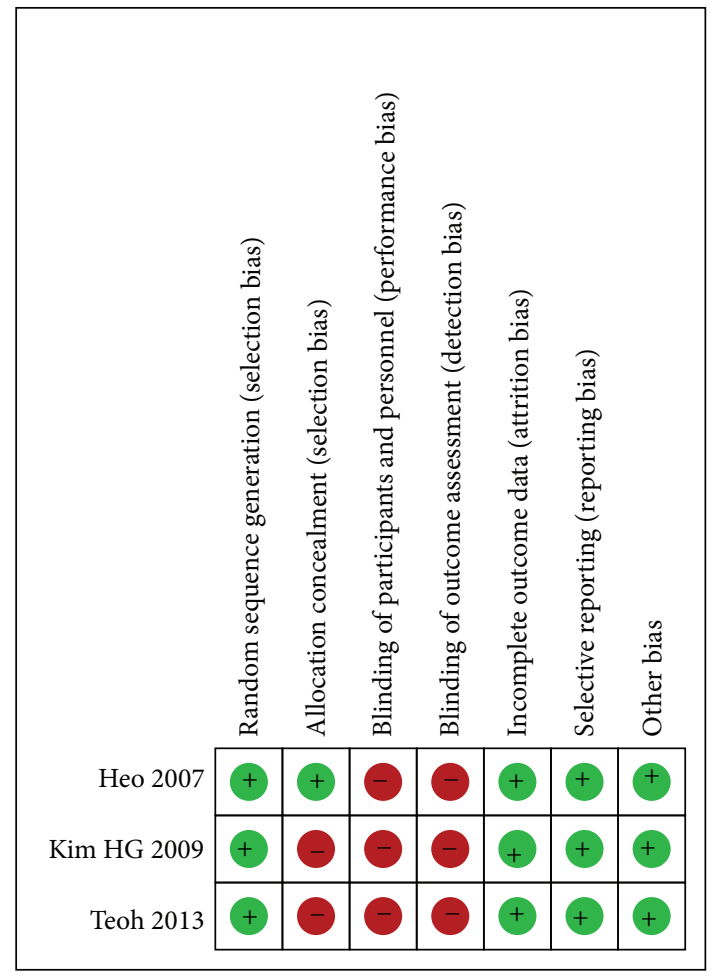

FIGURE 2: Risk of bias summary of randomized clinical trials.

high methodological quality $[16,19,21]$ and one of moderate methodological quality (Table 2) [18]. There appeared to be a consistent performance bias among all three randomized trials because of the fact that the nature of the study precludes blinding of the operator. Two studies were also limited by selection bias because of inadequate allocation concealment (Figure 2) [19, 20]. 


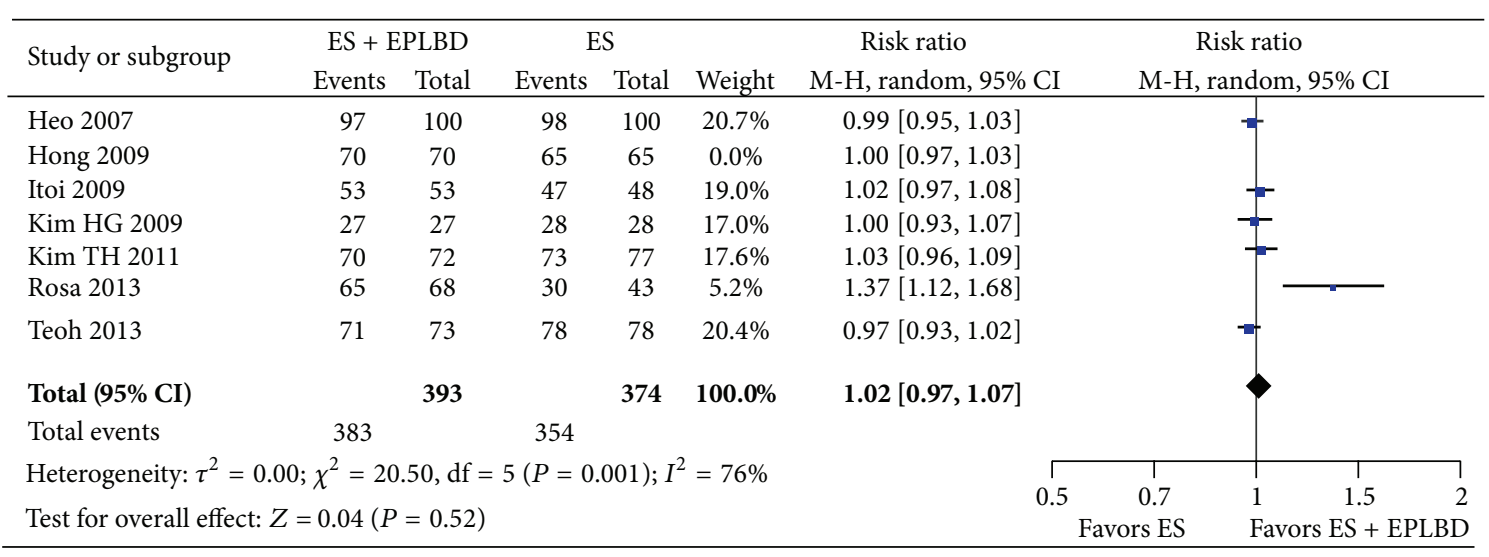

FIGURE 3: Forrest plot of the pooled risk ratio of overall clearance of duct stones and $I^{2}$ statistic for heterogeneity.

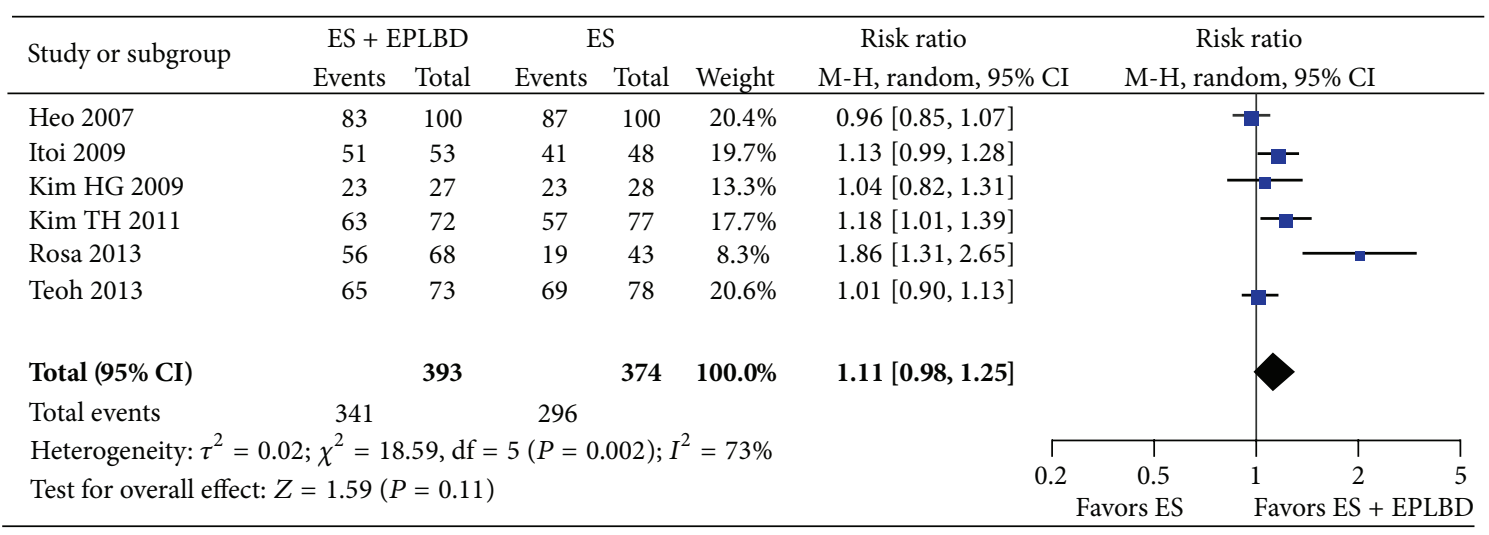

FIGURE 4: Forrest plot of the pooled risk ratio of clearance of stone at 1st session and $I^{2}$ statistic for heterogeneity.

TABLE 2: The Newcastle-Ottawa quality assessment in retrospective studies.

\begin{tabular}{lccc}
\hline Study (year) & Selection & Comparability & Outcome/exposure \\
\hline Itoi (2009) & $* * * *$ & $* *$ & $* *$ \\
Hong GY (2009) & $* * *$ & N/A & $* *$ \\
Kim TH (2011) & $* * * *$ & $* *$ & $* *$ \\
Rosa (2013) & $* * * *$ & $* *$ & $* *$ \\
\hline
\end{tabular}

3.4. Data Synthesis. Seven studies involving 902 patients met the inclusion criteria. Of the 902 patients, 439 subjects were in the ES group, while 463 subjects underwent ES + EPLBD. The median stone diameter in the ES + EPLBD group was $16 \mathrm{~mm}$ compared to $15.3 \mathrm{~mm}$ in the ES group. The betweenstudy variability (i.e., heterogeneity) beyond what could be expected by sampling error was substantially high for the pooled RR of overall clearance rate, clearance at 1st session, and the use of mechanical lithotripsy; hence, the random effects model was used. The $I^{2}$ of the pooled RR of the overall complication rate was $0 \%$, which was not considered substantial heterogeneity as per a priori definition and thus the fixed effects model was used.

3.4.1. Overall Stone Clearance and Stone Clearance at 1st Session. The rate of overall stone clearance was not significantly different between the ES + EPLBD group and the ES group (98\% versus 95\%, $\mathrm{RR}=1.01[0.97,1.05] ; P=0.60)$ (Figure 3 ). Similarly, the rate of stone clearance at the 1st session was not significantly different between the ES + EPLBD group and the ES group (87\% versus 79\%, $\mathrm{RR}=1.11[0.98,1.25] ; P=0.11$ ) (Figure 4).

3.4.2. Number of Sessions, Need for Mechanical Lithotripsy, and Procedure Duration. Among the four studies $[17-19,21]$ that reported the mean number of sessions needed for complete stone clearance, there was a nonsignificant trend toward fewer sessions needed among those who underwent ES + EPLBD versus ES $(1.3 \pm 0.3$ versus $1.8 \pm 0.7, P=0.245)$. $\mathrm{ES}+\mathrm{EPLBD}$ was associated with a reduced need for ML compared to ES alone (15\% versus $32 \%$; RR $=0.49[0.32$, $0.74] ; P=0.0008$ ) (Figure 5). Total procedure time was numerically shorter in the ES + EPLBD group in each of the three studies that reported this variable $[16,17,20]$, though this was statistically significant in only one study [16]. Total fluoroscopy time was significantly shorter in the ES + EPLBD group in the single study that reported this variable [16].

3.4.3. Adverse Events. ES + EPLBD was associated with a reduction in the overall rate of adverse events compared to ES alone (11\% versus $18 \%$; $R=0.58[0.41,0.81] ; P=0.001)$ 


\begin{tabular}{|c|c|c|c|c|c|c|c|c|c|}
\hline \multirow{2}{*}{ Study or subgroup } & \multicolumn{2}{|c|}{ ES + EPLBD } & \multicolumn{2}{|c|}{ ES } & \multicolumn{2}{|r|}{ Risk ratio } & \multirow{2}{*}{\multicolumn{2}{|c|}{$\begin{array}{c}\text { Risk ratio } \\
\text { M-H, random, 95\% CI }\end{array}$}} & \\
\hline & Events & Total & Events & Total & Weight & $\mathrm{M}-\mathrm{H}$, random, $95 \% \mathrm{CI}$ & & & \\
\hline Heo 2007 & 8 & 100 & 9 & 100 & $12.6 \%$ & $0.89[0.36,2.21]$ & $\rightarrow$ & & \\
\hline Hong 2009 & 13 & 70 & 47 & 65 & $0.0 \%$ & $0.26[0.15,0.43]$ & & & \\
\hline Itoi 2009 & 3 & 53 & 12 & 48 & $8.0 \%$ & $0.23[0.07,0.75]$ & - & & \\
\hline Kim HG 2009 & 9 & 27 & 9 & 28 & $16.5 \%$ & $1.04[0.49,2.21]$ & - & & \\
\hline Kim TH 2011 & 6 & 72 & 15 & 77 & $13.0 \%$ & $0.43[0.18,1.04]$ & $\longrightarrow-$ & & \\
\hline Rosa 2013 & 10 & 68 & 16 & 43 & $18.7 \%$ & $0.40[0.20,0.79]$ & -- & & \\
\hline Teoh 2013 & 21 & 73 & 36 & 78 & $31.2 \%$ & $0.62[0.40,0.96]$ & - & & \\
\hline Total $(95 \%$ CI $)$ & & 393 & & 374 & $100.0 \%$ & $0.57[0.40,0.83]$ & $>$ & & \\
\hline Total events & 57 & & 97 & & & & & & \\
\hline \multicolumn{6}{|c|}{ Heterogeneity: $\tau^{2}=0.06 ; \chi^{2}=7.26, \mathrm{df}=5(P=0.20) ; I^{2}=31 \%$} & 0.01 & 0.1 & 10 & 100 \\
\hline \multicolumn{6}{|c|}{ Test for overall effect: $Z=2.97(P=0.003)$} & Favo & $S+E P L B D$ & Favors ES & \\
\hline
\end{tabular}

FIGURE 5: Forrest plot of the pooled risk ratio of the use of mechanical lithotripsy and $I^{2}$ statistic for heterogeneity.

\begin{tabular}{lcccccccc}
\hline \multirow{2}{*}{ Study or subgroup } & \multicolumn{3}{c}{ ES + EPLBD } & \multicolumn{2}{c}{ ES } & \multicolumn{2}{c}{ Risk ratio } \\
Events & Total & Events & Total & Weight & M-H, fixed, 95\% CI & \multicolumn{2}{c}{ Risk ratio } \\
M-H, fixed, 95\% CI
\end{tabular}

FIGURE 6: Forrest plot of the pooled risk ratio of the overall rate of adverse events and $I^{2}$ statistic for heterogeneity.

TABLE 3: Subgroup analysis of the complications rate.

\begin{tabular}{lcccc}
\hline & ES & ES + EPLBD & RR, $(95 \%$ CI $)$ & $P$ value \\
\hline All bleeding & $38 / 439$ & $20 / 463$ & $0.5(0.3,0.8)$ & 0.01 \\
Pancreatitis & $29 / 439$ & $23 / 463$ & $0.8(0.4,1.3)$ & 0.29 \\
Perforation & $3 / 439$ & $0 / 463$ & Not estimable & \\
Cholangitis & $4 / 439$ & $4 / 463$ & $1.0(0.24,3.77)$ & 0.94 \\
\hline
\end{tabular}

(Figure 6). A subgroup analysis showed a significantly lower overall bleeding rate in the ES + EPLBD group (4\% versus $9 \% ; \mathrm{RR}=0.5[0.3,0.8] ; P=0.003)$. Bleeding could be further stratified into intraprocedural bleeding and clinically significant bleeding. The rate of intraprocedural bleeding was significantly higher in the ES alone group (8\% versus $4 \%, P=0.008)$, and while the rate of clinically significant bleeding was also numerically higher in the ES alone group, this trend did not attain statistical significance $(0.9 \%$ versus $0.3 \%, P=0.19)$. Individual studies generally required a 2-3 gram decrease in hemoglobin and/or overt melena for bleeding to be classified as "clinically significant." The rates of pancreatitis, perforation, and cholangitis were similar between the two groups (Table 3). No instances of perforation occurred in the 463 patients undergoing ES + EPLBD. Three perforations occurred in the ES arm: one retroperitoneal perforation of a diverticular wall during ES [19] and two suspected guidewire perforations [20]. All three perforations were managed conservatively. With regard to pancreatitis, a subanalysis demonstrated no difference in the rate of severe pancreatitis between patients undergoing ES versus ES + EPLBD $(1.2 \%$ versus $0.7 \%, P=0.7)$ [15, 17, 20, 21]. No lifethreatening complications were reported across all patients in both groups.

3.4.4. Sensitivity Analyses. Sensitivity analyses were performed and most of the heterogeneity observed for the calculation of pooled overall clearance rate and clearance at 1st session could be attributed to a single study [21]. However, removing this study from the analysis did not alter the results. Similarly, no significant changes were seen across all outcomes when the study published only in abstract form was removed [18]. The retrospective and prospective studies were also analyzed separately. The pooled RR estimates for all primary and secondary outcomes when analyzed separately for only retrospective studies and for only prospective studies were concordant with pooled RR estimates for all of the studies combined (Table 4). A funnel plot of the overall clearance rate showed some asymmetry due to an unusually low rate of overall clearance (70\%) in the ES-only arm in the study conducted by Rosa et al. (see Figure 7) [21]. 
TABLE 4: Sensitivity analysis of the primary and secondary outcomes stratified by the type of the studies.

\begin{tabular}{lccr}
\hline & & Relative risk (EPLBD + ES versus ES), (95\% CI) & Combined \\
& Retrospective studies & $0.98(0.97,1.01)$ & $1.01(0.97,1.05)$ \\
Overall clearance of bile duct stone & $1.06(0.95,1.01)$ & $0.99(0.91,1.07)$ & $1.11(0.98,1.25)$ \\
Clearance of the stones at 1st session & $1.29(1.01,1.46)$ & $0.73(0.52,1.03)$ & $0.49(0.32,0.74)$ \\
Need for ML & $0.31(0.22,0.44)$ & $0.59(0.36,0.95)$ & $0.58(0.41,0.81)$ \\
Overall complication rate & $0.57(0.36,0.91)$ & & \\
\hline
\end{tabular}

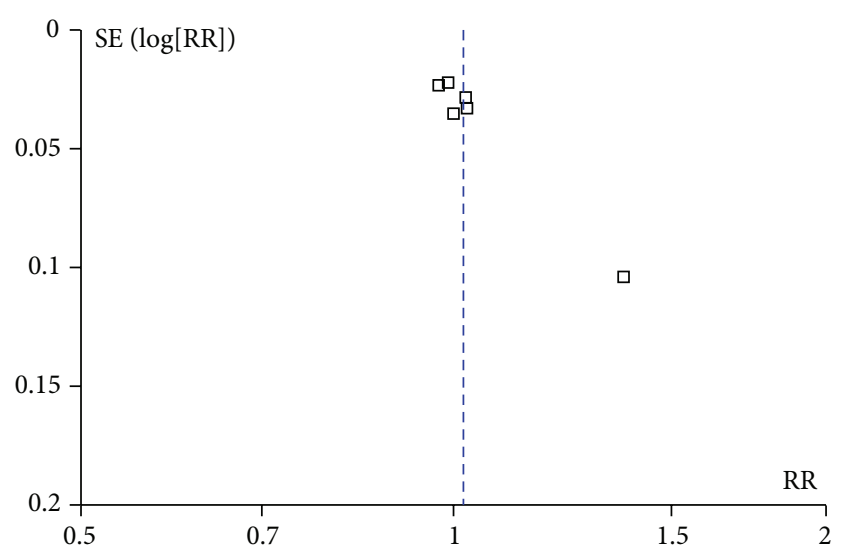

FIGURE 7: Funnel plot of the risk ratio of the overall clearance of bile duct stones.

\section{Discussion}

Approximately $85 \%-90 \%$ of bile duct stones can be removed with a balloon or basket following ES, with the most common reason for failure being large stone size $[2,22]$. Historically, stones $>10 \mathrm{~mm}$ in diameter, and especially stones $>15 \mathrm{~mm}$ in diameter, have been associated with a lower success rate for endoscopic removal and a more frequent need for lithotripsy $[3,23]$. Beyond stone size, factors such as small diameter of the distal CBD, ductal strictures distal to stones, and inadequate sphincterotomy, all may negatively impact the success rate of stone extraction at ERCP.

Despite the fact that the studies populating this metaanalysis were enriched with patients harboring large bile duct stones, we observed very high rates of success for overall duct clearance for both EPLBD after ES (98\%) and for ES alone (95\%). This likely reflects the expertise of the centers conducting these trials. Nonetheless, there was a trend observed towards more frequent clearance of the duct in one session with EPLBD after ES (87\%) as compared with ES alone $(79 \%, \mathrm{RR}=1.11[0.98,1.25] ; P=0.11)$. As such, it remains possible that rates of single session duct clearance may be enhanced with EPLBD after ES.

While mechanical lithotripsy is a valuable tool in the management of large or difficult stones, there are also potential issues associated with this technique including the challenge of cannulation with a through-the-scope lithotripter, difficulty with stone capture, need for repeated duct sweeping to remove stone fragments, and the potential need for stent placement if adequate duct clearance is not attained. EPLBD after ES holds potential advantages over ML in that many of these issues are avoided, as cannulation with the dilating balloon is not difficult, distal obstructive phenomena (e.g., duct strictures and inadequate sphincterotomies) are treated, and stones are removed in toto. As a result, stone clearance might be accomplished more quickly with this technique.

In this meta-analysis we found a significant reduction in the need for ML when EPLBD was employed after ES (15\%) as compared with ES alone (32\%). Limitations in data reporting preclude firm conclusions regarding time savings, but trends were noted for reductions in total procedure time and fluoroscopy time in the ES + EPLBD group when these variables were reported.

The use of EPLBD after ES was also associated with a reduction in the overall rate of adverse events as compared with ES alone. However, at least some of these differences appeared to be due to differences in intraprocedural bleeding events. Establishing a consistent threshold for reporting this endpoint is difficult, and for the endpoint of clinically significant bleeding, which may be more relevant, there was not a significant difference between the two groups. The rates for pancreatitis and cholangitis were similar between the two groups, and there were no perforations in the 463 patients who underwent ES + EPLBD. As such, it appears that ES + EPLBD is at least as safe as, and may be safer than, ES alone in patients undergoing ERCP for large bile duct stones.

A recently published meta-analysis [24] similarly aimed to compare ES alone versus ES + EPLBD. However, this meta-analysis is hindered by significant flaws with regard to study eligibility, inclusion criteria, and quality assessment that collectively detract from its overall validity. In this analysis, the authors erroneously included one study which was a randomized clinical trial of ES versus primary balloon sphincteroplasty (no preceding ES) using smaller balloons that did not exceed $12 \mathrm{~mm}$ in diameter [25]. The analysis also inappropriately included a randomized trial that compared $\mathrm{ES}+\mathrm{EPLBD}$ versus $\mathrm{ES}+$ mechanical lithotripsy; in this study, no patients who underwent ES + EPLBD could receive $\mathrm{ML}$, whereas all patients in the ES arm underwent ML also [26]. Another methodological concern involves the use of the Jadad score (an assessment tool only validated for assessing the quality of randomized clinical trials) to evaluate two retrospective studies [16, 19]. Finally, the authors reported that five studies in their analysis were "double blinded"an impossibility given the nature of the interventions. These shortcomings grossly invalidate the findings of this analysis and the data we present represents the first methodologically robust meta-analysis comparing these two techniques.

The pooled results from this analysis are consistent with the trend from the majority of the included studies, which 
lacked adequate sample size to reach statistical significance independently. The results of this meta-analysis appear generalizable, given the variety of clinical settings, patient diversity, relatively uniform, readily available devices, and simple technique used to perform EPLBD after ES.

There are limitations in this study that merit mention. The inclusion of only English language studies could have potentially excluded some relevant trials. Significant heterogeneity noticed between the studies may be related to variations in study design, participant selection, use of different balloon sizes for dilation, the extent of the sphincterotomy, and operator skill level with mechanical lithotripsy. However, a sensitivity analysis that removed one study at a time demonstrated no effect on the overall conclusion of the pooled analysis. Combining retrospective and prospective studies can be problematic and is only advisable if the segregated results of pooled analyses of the retrospective and prospective studies are consistent, which is the case in our analysis.

In conclusion, the available literature demonstrates that $\mathrm{ES}+\mathrm{EPLBD}$ has similar efficacy to ES alone for the removal of large bile duct stones while significantly reducing the need for ML. Further, ES + EPLBD appears to be safe, with a lower overall rate of complications in this pooled analysis relative to ES alone. ES + EPLBD should be considered a firstline technique in the management of large bile duct stones. Future prospective studies may allow for better comparisons between the two techniques with regard to total procedure time, fluoroscopy time, and costs.

\section{Conflict of Interests}

The authors of this paper report no conflicts of interests including, but not limited to, consulting fees, paid expert testimony, employment, grants, honoraria, patents, royalties, stocks, or other financial or material gains that may involve the subject matter of the paper.

\section{References}

[1] J. T. Maple, S. O. Ikenberry, M. A. Anderson et al., "The role of endoscopy in the management of choledocholithiasis," Gastrointestinal Endoscopy, vol. 74, no. 4, pp. 731-744, 2011.

[2] P. B. Cotton, "Non-operative removal of bile duct stones by duodenoscopic sphincterotomy," The British Journal of Surgery, vol. 67, no. 1, pp. 1-5, 1980.

[3] A. Lauri, R. C. Horton, B. R. Davidson, A. K. Burroughs, and J. S. Dooley, "Endoscopic extraction of bile duct stones: management related to stone size," Gut, vol. 34, no. 12, pp. 1718-1721, 1993.

[4] G. Ersoz, O. Tekesin, A. O. Ozutemiz, and F. Gunsar, "Biliary sphincterotomy plus dilation with a large balloon for bile duct stones that are difficult to extract," Gastrointestinal Endoscopy, vol. 57, no. 2, pp. 156-159, 2003.

[5] A. Minami, S. Hirose, T. Nomoto, and S. Hayakawa, "Small sphincterotomy combined with papillary dilation with large balloon permits retrieval of large stones without mechanical lithotripsy," World Journal of Gastroenterology, vol. 13, no. 15, pp. 2179-2182, 2007.
[6] A. Maydeo and S. Bhandari, "Balloon sphincteroplasty for removing difficult bile duct stones," Endoscopy, vol. 39, no. 11, pp. 958-961, 2007.

[7] P. V. Draganov, W. Evans, A. Fazel, and C. E. Forsmark, "Large size balloon dilation of the ampulla after biliary sphincterotomy can facilitate endoscopic extraction of difficult bile duct stones," Journal of Clinical Gastroenterology, vol. 43, no. 8, pp. 782-786, 2009.

[8] G. A. Wells, B. Shea, D. O'Connell et al., “The Newcastle-Ottawa Scale (NOS) for assessing the quality of nonrandomised studies in meta-analyses," http://www.ohri.ca/programs/clinical_epidemiology/oxford.asp.

[9] “Database C. Review Manager (RevMan)," http://ims.cochrane .org/revman.

[10] N. Mantel and W. Haenszel, "Statistical aspects of the analysis of data from retrospective studies of disease," Journal of the National Cancer Institute, vol. 22, no. 4, pp. 719-748, 1959.

[11] R. DerSimonian and N. Laird, "Meta-analysis in clinical trials," Controlled Clinical Trials, vol. 7, no. 3, pp. 177-188, 1986.

[12] J. P. Higgins and S. G. Thompson, "Quantifying heterogeneity in a meta-analysis," Statistics in Medicine, vol. 21, no. 11, pp. 1539$1558,2002$.

[13] T. B. Huedo-Medina, J. Sánchez-Meca, F. Marín-Martínez, and J. Botella, "Assessing heterogeneity in meta-analysis: Q statistic or I2 Index?” Psychological Methods, vol. 11, no. 2, pp. 193-206, 2006.

[14] J. García-Cano, L. T. Arana, C. J. Ayllón et al., "Biliary sphincterotomy dilation for the extraction of difficult common bile duct stones," Revista Española de Enfermedades Digestivas, vol. 101, no. 8, pp. 541-545, 2009.

[15] J. H. Heo, D. H. Kang, H. J. Jung et al., "Endoscopic sphincterotomy plus large-balloon dilation versus endoscopic sphincterotomy for removal of bile-duct stones," Gastrointestinal Endoscopy, vol. 66, no. 4, pp. 720-726, 2007.

[16] T. Itoi, F. Itokawa, A. Sofuni et al., "Endoscopic sphincterotomy combined with large balloon dilation can reduce the procedure time and fluoroscopy time for removal of large bile duct stones," The American Journal of Gastroenterology, vol. 104, pp. 560-565, 2009.

[17] H. G. Kim, Y. K. Cheon, Y. D. Cho et al., "Small sphincterotomy combined with endoscopic papillary large balloon dilation versus sphincterotomy," World Journal of Gastroenterology, vol. 15, no. 34, pp. 4298-4304, 2009.

[18] G. Y. Hong, S. W. Park, K. S. Seo, and H. Moon, "Endoscopic sphincterotomy plus large-balloon dilation versus endoscopic sphincterotomy for removal of large common bile duct stones," Gastrointestinal Endoscopy, vol. 69, Article ID AB148, 2009.

[19] T. H. Kim, H. J. Oh, J. Y. Lee, and Y. W. Sohn, "Can a small endoscopic sphincterotomy plus a large-balloon dilation reduce the use of mechanical lithotripsy in patients with large bile duct stones?" Surgical Endoscopy, vol. 25, no. 10, pp. 3330-3337, 2011.

[20] A. Y. Teoh, F. K. Cheung, B. Hu et al., "Randomized trial of endoscopic sphincterotomy with balloon dilation versus endoscopic sphincterotomy alone for removal of bile duct stones," Gastroenterology, vol. 144, no. 2, pp. 341-345.el, 2013.

[21] B. Rosa, P. Moutinho-Ribeiro, A. Rebelo, A. Pinto-Correia, and J. Cotter, "Endoscopic papillary balloon dilation after sphincterotomy for difficult choledocholithiasis: a case-controlled study," World Journal of Gastrointestinal Endoscopy, vol. 5, no. 5, pp. 211-218, 2013. 
[22] K. F. Binmoeller, M. Bruckner, F. Thonke, and N. Soehendra, "Treatment of difficult bile duct stones using mechanical, electrohydraulic and extracorporeal shock wave lithotripsy," Endoscopy, vol. 25, no. 3, pp. 201-206, 1993.

[23] J. J. Bergman, E. A. Rauws, P. Fockens et al., "Randomised trial of endoscopic balloon dilation versus endoscopic sphincterotomy for removal of bileduct stones," The Lancet, vol. 349, no. 9059, pp. 1124-1129, 1997.

[24] Y. Feng, H. Zhu, X. Chen et al., "Comparison of endoscopic papillary large balloon dilation and endoscopic sphincterotomy for retrieval of choledocholithiasis: a meta-analysis of randomized controlled trials," Journal of Gastroenterology, vol. 47, no. 6, pp. 655-663, 2012.

[25] C.-K. Lin, K.-H. Lai, H.-H. Chan et al., "Endoscopic balloon dilatation is a safe method in the management of common bile duct stones," Digestive and Liver Disease, vol. 36, no. 1, pp. 68-72, 2004.

[26] G. Stefanidis, N. Viazis, D. Pleskow et al., "Large balloon dilation vs. mechanical lithotripsy for the management of large bile duct stones: a prospective randomized study," The American Journal of Gastroenterology, vol. 106, pp. 278-285, 2011. 


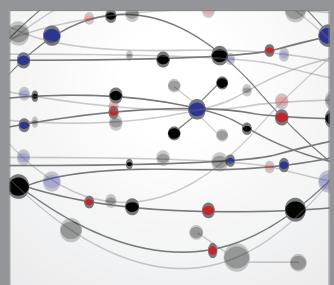

The Scientific World Journal
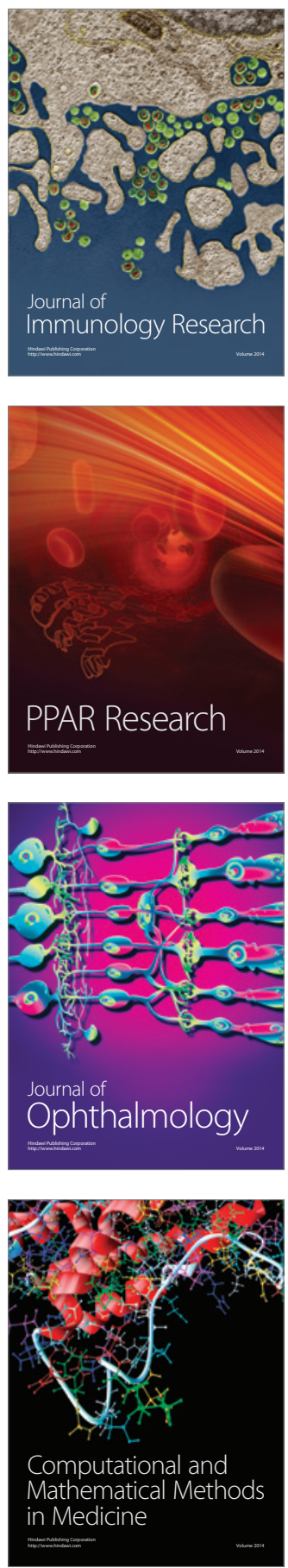

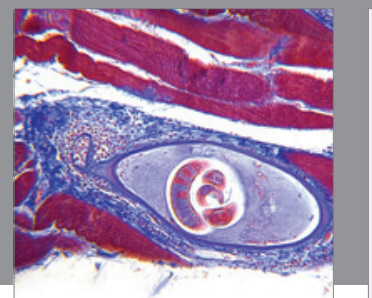

Gastroenterology

Research and Practice
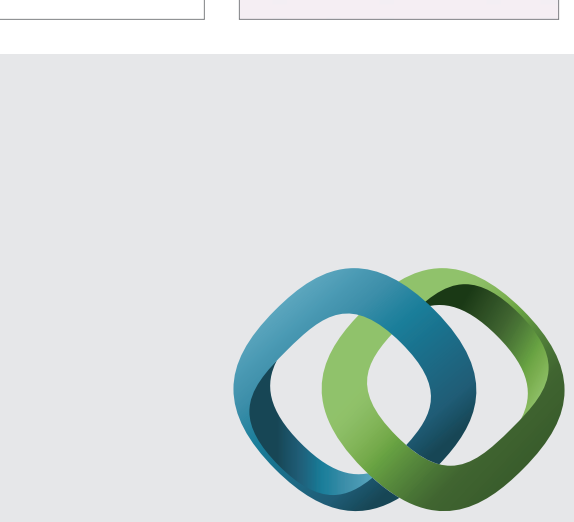

\section{Hindawi}

Submit your manuscripts at

http://www.hindawi.com
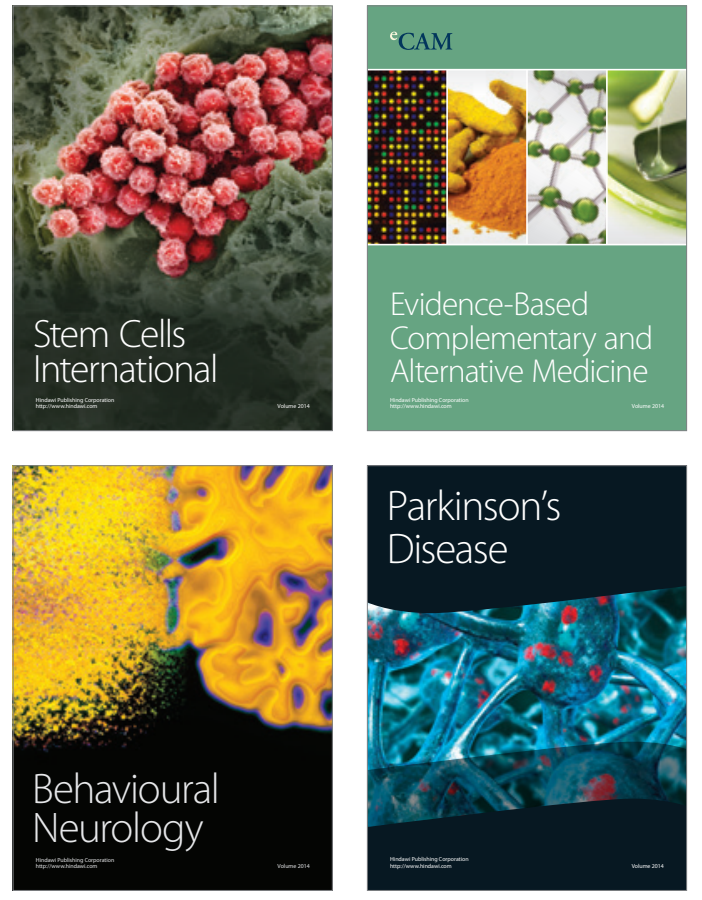
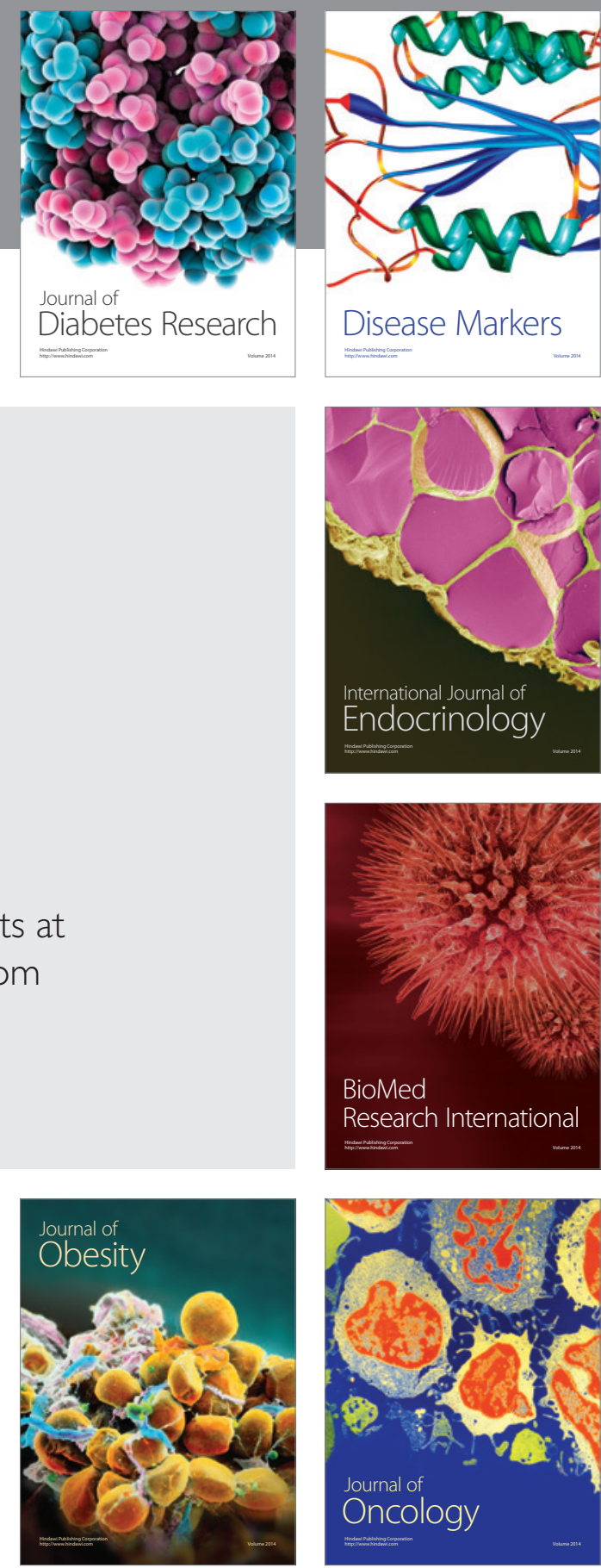

Disease Markers
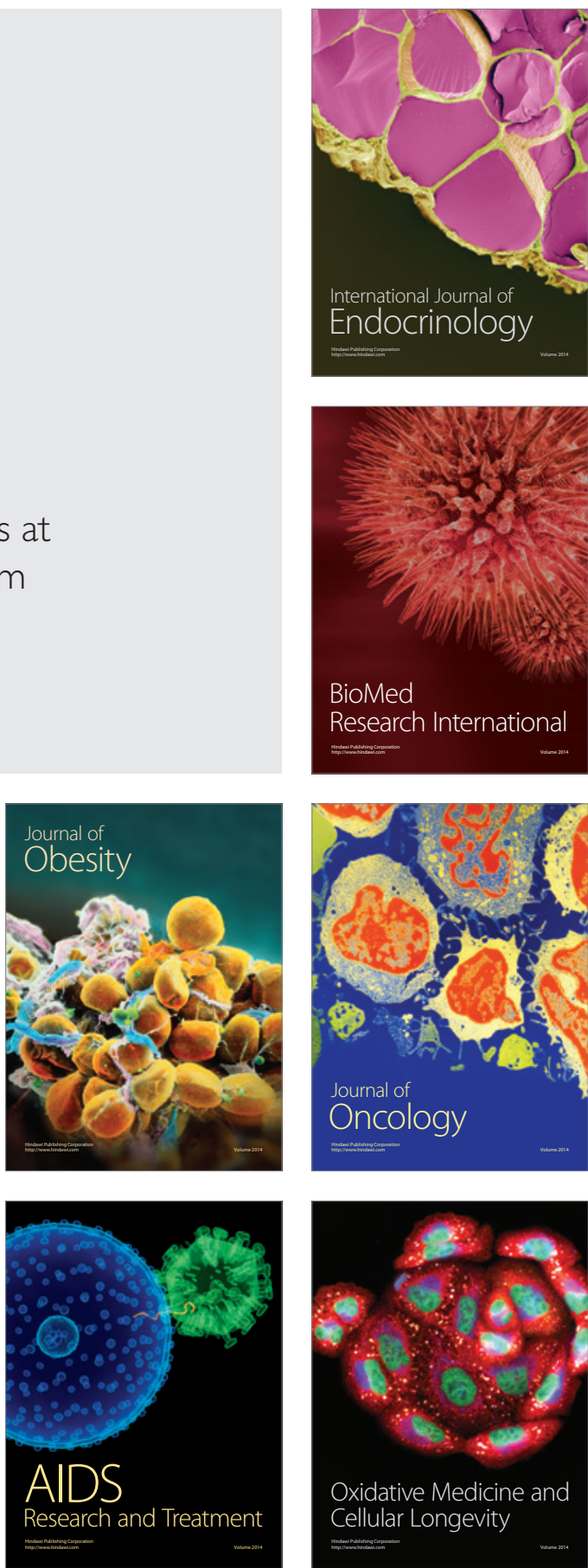